\title{
Analysis on the Development of Simplification About Modern Architectural Ornament and Its Social Effects
}

\author{
Chen Jiang \\ Jingdezhen Ceramic Institute \\ Jingdezhen, China 333403
}

\begin{abstract}
Objective: Explore the social mechanism of simplified architectural ornament style. Method The development of simplification about modern architectural ornament has been teased out, and the deep reasons of its formation are analyzed in detail by using modern aesthetic theory, psychological theory and sociology theory. Conclusion: The formation of the simplified style of modern architectural ornament is the combined result of social economy, technology, art, culture and other factors. It is the inevitable requirement of the development of history and provides a reference for understanding the new phenomenon of urban architecture.
\end{abstract}

Keywords—simplification; aesthetic effect; psychological effect; cost effect

\section{INTRODUCTION}

Architectural ornament is relative to architectural structure, aiming to protect the main structure of the building, improve the physical properties of the building, beautify the building environment, and use decoration materials or ornaments to handle the inner and outer surface and space of the building, and thus make the user feel pleased. In modern times, with the development of the economy, the living state of modern society has gradually deviated from the people's original intention, and the spiritual load brought by the pressure of survival makes people have no time to look back on their own hearts [1]. In this context, people's attitudes towards architectural ornament have also undergone fundamental changes that architectural ornament has changed from complexity to simplicity, and simplification has become the pronoun of modern architecture. The increasingly simplification of architectural style is in sharp contrast to the complexity of human technological development. The main reason lies in the deeper social factors besides the technical conditions. The factors such as economy, technology, aesthetics, culture and so on directly contribute to the simplification development of modern architectural ornament.

\section{THE DEVELOPMENT OF SIMPLIFICATION ABOUT MODERN ARCHITECTURAL ORNAMENT AND ITS CHARACTERISTICS}

Throughout the history of construction development, the progress of architectural civilization is always closely related to the development of social productive forces. Every change of technology not only provides new materials and technology for buildings, but also has a huge impact on the appearance [2].
The development of modern architecture also follows such a rule. The process of architectural ornament simplification mainly goes through the following stages.

\section{A. Germination and Exclusion}

The development of modern architectural ornament is closely related to the development of modern design, which movement began in Britain in 1850s. The "Arts and Crafts Movement", represented by William Maurice, opened the design and development path suitable for the modern industrial system under the large-scale industrial background [3]. During that time, the architectural design was also under changes - the application of new materials such as steel and glass, the improvement of the long-span steel frame structure and the implementation of the assembly system lead to the huge changes in architecture world, and finally gave birth to a unique building, "Crystal Palace", see "Fig. 1". The meaning of "Crystal Palace" is that it completely subverted the concept of architectural form in the past, displayed a completely new appearance in front of the world, formed a completely different architectural style from the period of Vitoria, see "Fig 2" and opened the development path of modern architecture.

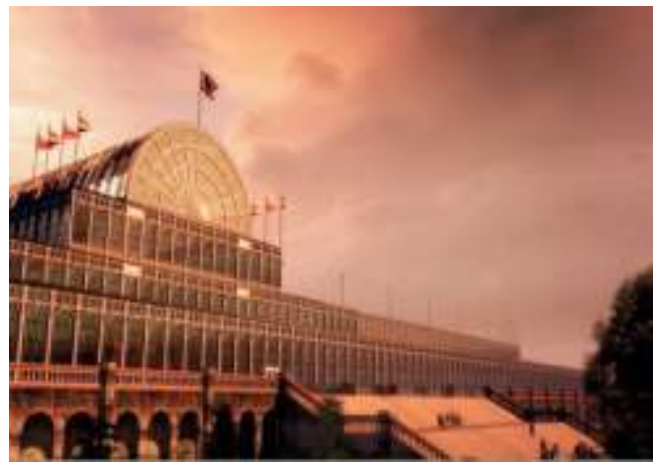

Fig. 1. "Crystal palace" rendering. 


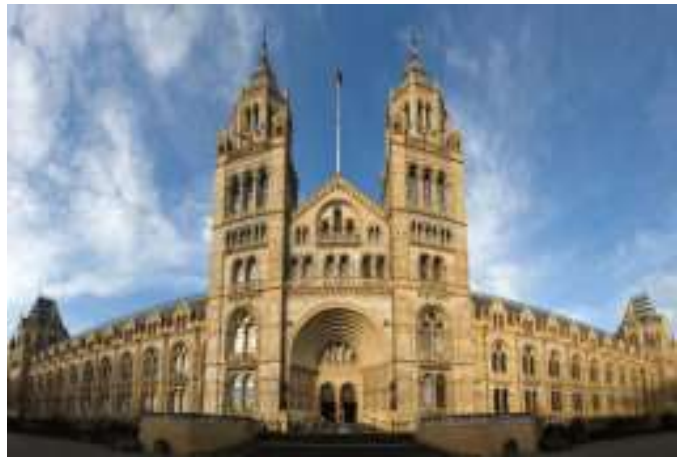

Fig. 2. The history museum of Britain.

Of course, the emergence of new things is always accompanied with great criticism; "Crystal Palace" was of no exception. People regarded it as a huge and ugly architecture situated in the park like a grave, with no classical architectural beauty, even the designer Joseph Paxton received many verbal attacks from some radical groups. However, the emergence of new things, after all, has its logic. The construction of the "Crystal Palace" is the inevitable result of the application of new materials and new technologies in the field of architecture. Although it was contentious, it opened the prelude to modern architecture and inspired people to think about how to coordinate the relationship between ornament and function under the new technical conditions.

\section{B. Revision and Acceptance}

With the development of science and technology, people began to try to accept this new type of architecture, no longer exclude its existence. But the conventional thinking made people intend to transform them in a traditional way to meet the old aesthetic concepts, therefore, "Art-nouveau Movement" with the theme of ornament was set off in the late 19th Century and early 20th Century, tried to modify modern architecture with ornament to meet the requirements of "beauty". Although it still emphasized ornament, the form of ornament has changed and the ornament techniques has abandoned the complex and complicated ornament details of Vitoria Period and turned to some natural ornaments instead. Take the representative figure Victor Horta during the Artnouveau Movement as an example, curved flowers and branches were often used to achieve romantic decoration effect in "Fig. 3". Although there was clear trace of ornament in the architectures of Horta's design, the ornament style has changed that the abstract curves replaced the tedious details. The grand narrative like architectural sculpture was replaced by a small and fresh architecture style, which reflects that the architectural ornament of the Art-nouveau Movement period was changing from tedious to simplicity gradually.

\section{Expanding and Prosperity}

Just like a growing body cannot adapt to old clothes, gradually strong physique is bound to break through the old fetters and get new life. The new building flourished in the context of industrialization of large machines, and the old ornament style was unable to adapt to the rapid social changes obviously, therefore, change became an inevitable choice. The design movement of "Modernism" was conceived and developed in such soil, with the slogan of "form follows function", affected the development of architecture for more than half a century since then[5]. The extensive application of the modular system and the mechanization of the assembly process made the production efficiency of the architecture industry greatly improved, and the decorative craft that was stuck in the traditional manual operation has obviously been unable to adapt to this great industrial change, so it gradually being replaced by the style that can adapted to the modern architecture structure and technology - simplicity, concise and natural in "Fig. 4". This simple style is not only refreshing, but more importantly, it fits perfectly with the efficiency requirements of the modern construction industry. When saturated seeds meet suitable soil, vigorous development is inevitable. Although various post-modernism architectural movements have sprung up, the essence was an amendment to modernism. The foundation of the "form follows function" advocated by modernism has not changed, and the architectural ornament has not returned to the tedious style of the Victoria period, simplicity has been the mainstream style after the "modernist architecture" [6].

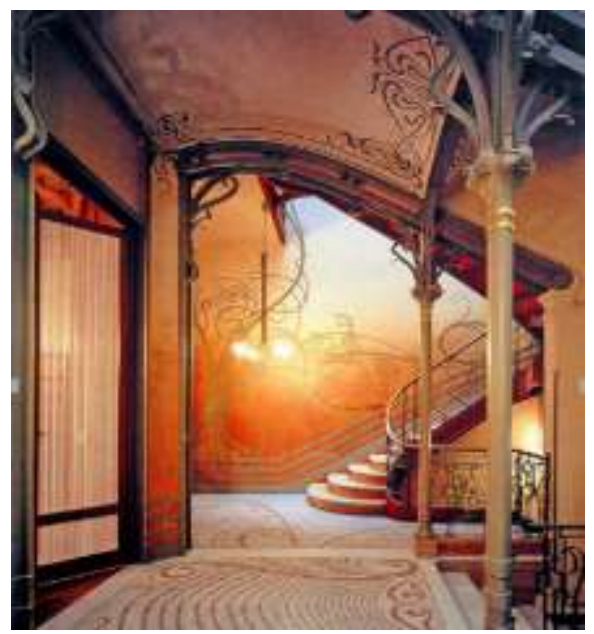

Fig. 3. Cyrus residence interior.

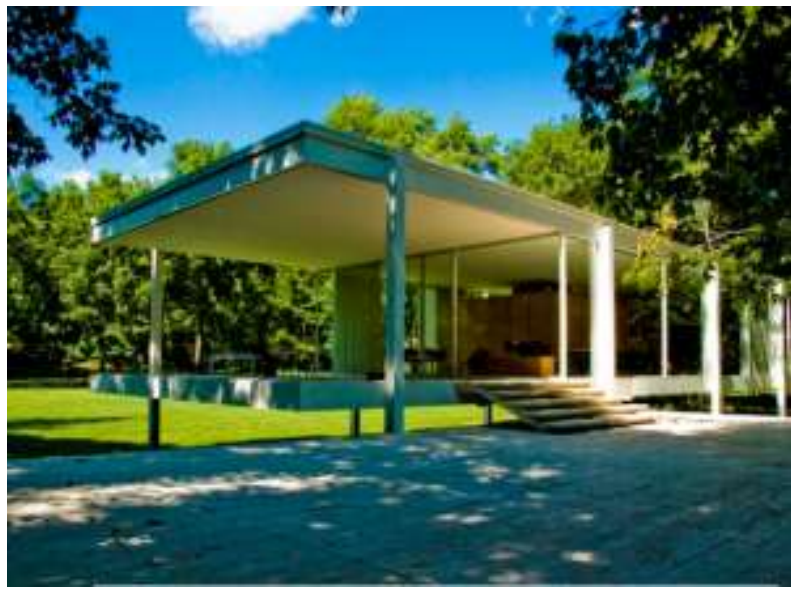

Fig. 4. Farnsworth house. 


\section{THE “THREE DIMENSIONAL EFFECT” OF MODERN ARCHITECTURAL ORNAMENT SIMPLIFICATION}

Modern architectural simplification has brought the threedimensional effect to the society, while modern architectural ornament has also been restricted by many factors, such as economic, technical, aesthetic, and cultural and so on. The role of ornament has also attracted lots of controversy, which contains deeper social reasons besides technical conditions. These factors also bring up the rapid development for modern architectural ornament simplification. The relationship between modern architectural simplification and its social effects is shown in "Fig. 5".

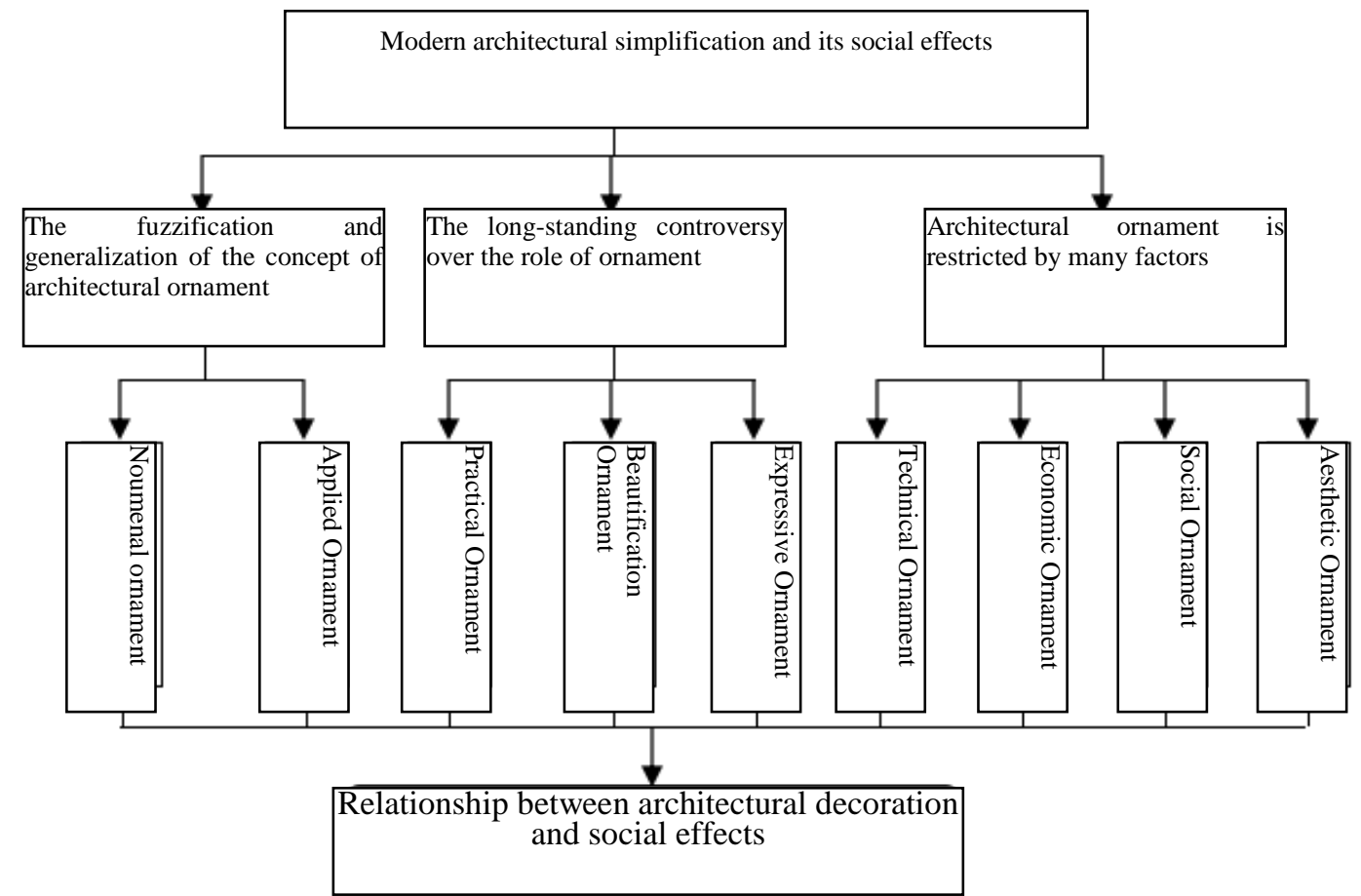

Fig. 5. The table of relationship between modern architectural simplification and social effects.

\section{A. The "Social Aesthetic Effect" of Architectural Ornament Simplification}

The fundamental purpose of design is to create practical, comfortable and beautiful products for mankind. As an important category in the field of design, architectural design itself also follows the essential requirements of general design that aesthetics is also an important factor for its consideration [7].

Before the industrial revolution, the traditional architecture with exquisite ornament was fond by people. As a form of beauty, modern architecture that is simple has been favored by modern people. The existence of such a difference is closely related to the architectural environment of the past and the present. Before going deep into the relationship between architectural environment and beauty, we need to have a simple understanding of people's attitudes in choosing "beauty". From an aesthetic point of view, beauty is a psychological feeling that makes people feels secure and harmonious. People's choices toward "beauty" objects tend to be those have clear significance and sharp contrast between the foreground and background, which convey accurate and clear messages and avoid visual confusion, and give people a sense of visual stability. Using this principle, we can analyze the architectural environment. Before the industrial revolution, the productive forces were relatively backward, and the social materials were not abundant. The construction of large buildings was a time and financial consuming work that the contractors can only be some wealthy businessmen, aristocrats or some powerful departments. Therefore, the discourse power of construction was basically mastered in the hands of a few powers, making the building a symbol of a certain social power and wealth, so the exquisite ornament was essential to fit the social significance attached to the building.

As a few large and beautifully decorated buildings, they are in a prominent position along the skyline of the whole city. In a small city, there are only one or two large buildings, which are the most important information communicators of the whole city. Therefore, contractors hope to build splendid and stunning architectures, strengthen the main position of these architectures, and make them become the visual center of the whole city, see "Fig. 6". With the continuous increase of social wealth and improvement of architectural technology, the volume of city is growing bigger and bigger, and more and more buildings are built, and the forms are even more diverse. Especially in some large cities with large skyscrapers, the simple skyline is no longer there, instead with the complicated and varied urban profile, see "Fig. 7". Even in some areas, the prospect and background of the city have become blurred that being intertwined and interdependent. So in a complex urban organism, the information stored is also very complicated. People need to deal with more information in this huge system, 
and as the main component of the building, the details of the surface should be treated as simple as possible to reduce unnecessary information load, which can improve the efficiency of information processing. This is an inevitable choice for complex urban organic bodies.

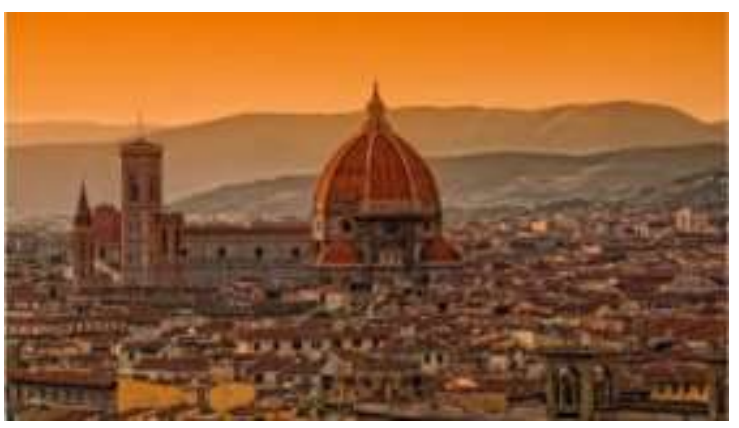

Fig. 6. Florence ancient city.

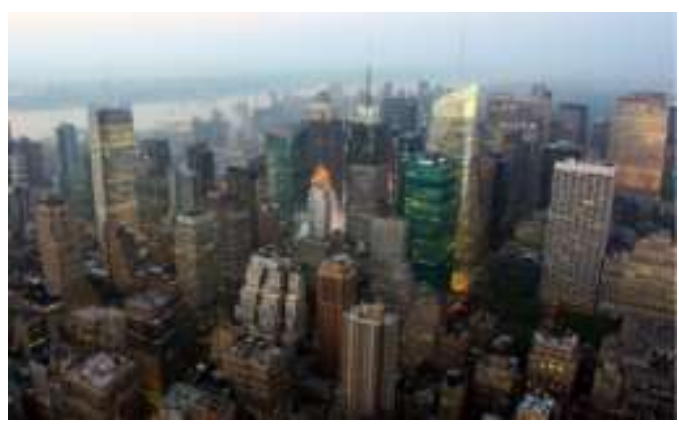

Fig. 7. Manhattan, New York.

\section{B. The "Social Psychological Effect" of Architectural Ornament Simplification}

As mentioned above, people's dealing with visual information is actually a process of active selection, that is, under certain conditions, extract the required information quickly and accurately. The clear and natural information field of the environment is the best state. While the information field of the environment is not so clear, people need to spend more energy to identify the required information. When this stress reaction exceeds a certain load, people will produce boredom, anxiety and other negative emotions. With the help of "Gestalt theory" of Gestalt psychology, we can explain the reasons for the simplification of modern architectural ornament.

"Gestalt theory" considers that the "shape" of things is neither the objective existence nor the generalized form of art, but a kind of image organization and structure formed in the perceptual experience of human beings. It is the overall feeling of the audience's experience and judgments in the process of cognition, and is the product of the combination of subjective cognition and objective object. "Gestalt theory" well explains the compensation mechanism in visual information processing, that is, people's prior information is an organic whole deeply rooted in mind. When the present information breaks the original balance, the compensation mechanism in consciousness will be mobilized and the incomplete information is supplemented to achieve the effect of visual balance. Human subconscious consider the world as a harmonious whole, and if the harmony is broken, people would try to compensate by other ways to achieve the stable state in consciousness.

It is the "compensation mechanism" that led to the differences of architectural ornament from the past to now. In the past, because of the backwardness of technology and poor material supply, people lived a monotonous life and in the relatively empty spiritual world, which required the architect create a more exquisite "architectural world" under the existing technical conditions to respond to the demands of people for the spiritual world. With the development of scientific and technological civilization, the volume of the city has become huge and the city structure becomes complex. The architecture has already stripped the function of emotional education and returned to the most primitive function of using. It is because of the changes of architectural function that the added meaning of the original architectural ornament becomes unnecessary. People need simple ornament to improve the efficiency of information recognition in complex urban organisms and weaken the complex texture of the city with simple ornament. It is the "negative compensation mechanism" and the "simplification" of the building function makes the architectural ornament simplification as a natural choice.

\section{The "Social Cost Effect" of Architectural Ornament Simplification}

The modern construction industry developed and grew gradually under the background of the extremely prosperous commodity economy. One of the biggest characteristics of commodity economy is the maximization of interests, that is, to maximize profits at the lowest cost. As a part of the market economy, cost control in construction industry is a factor that must be considered, and the concern of cost is also an important reason for the simplification of architectural ornament [9].

First, as far as the large social environment is concerned, although the prosperity of the market economy has brought an unprecedented gathering of social wealth, the cost of maintaining the social operation is increasing at the same time. Taking municipal construction as an example, in addition to the traditional highway construction, all kinds of rail transportation, waterways and aviation construction that are huge systematic projects with large investments are also essential for modern cities, which cannot be compared in traditional cities. Therefore, the investment of urban construction should be accurately calculated and the limited funds should be used in more urban construction to achieve the goal of maximizing the economic and social effects. As an important part of urban construction, building construction (especially for public buildings) also needs to take cost effect into consideration. The more ornaments, the more manpower and material resources will be invested, but the amount of ornament will not have a substantial impact on the practical function of buildings. Therefore, for the sake of cost control, modern architecture basically adopts simple decoration treatment methods, so as to achieve the goal of cost saving.

Secondly, for a single building, the facilities of modern buildings are far more complex than traditional ones. For 
example, there are no electrical equipment, network communication equipment, HVAC equipment and so on in traditional buildings. These facilities are not a small investment, coupled with late maintenance costs are also factors that need to be considered in the construction cost. The necessary construction cost is increased, the additional construction cost will be reduced correspondingly, and reducing unnecessary ornament is the most effective way to control extra cost.

Thirdly, the simplification of architectural ornament is conducive to the cost control and optimal allocation of human resources. Although the level of mechanization and intellectualization of modern construction industry has been greatly improved, compared with other industries, construction industry still belongs to labor intensive industry, so does the field of decoration and ornament. With the increasing cost of human resources, effective optimization of human resources is one of the most effective ways to control cost, and reducing the input of human resources in building decoration is an effective way to control the cost of construction. In addition, as the process of urbanization is accelerating, more and more cities are entering the period of rapid development, which requires more manpower and material resources in urban construction. While with the continuous decline of birth rate and the decreasing number of labor force, there is a structural imbalance in the supply and demand of labor in some countries and regions. To solve this problem, on the one hand, we should expand the proportion of mechanized production and improve the production efficiency. On the other hand, we should optimize the existing allocation of human resources and put the limited resources into more construction, and reducing unnecessary building ornament is the most effective way to save labor resources

\section{CONCLUSION}

There are always some reasons for the existence and development of a phenomenon. For an activity that involved by people, the reason mainly lies in two aspects. One is the objective material and technological conditions and another is the subjective initiative of human beings. As for the simplification of architectural ornament, the deeper reason behind it is more of the latter. When the conditions of technology are solved, people's view towards problem is also more diversified, from the inner feelings of individual to the overall coordination of the whole society, examine the essence of the problem from a broader perspective, and thus provide a reference for the study of similar phenomena.

\section{REFERENCES}

[1] Wang Zhaoxia. Application of Minimalism in Product Design[J]. Packaging Engineering, 2016(10):168-169. 王朝侠. 极简主义在产品 设计中的应用研究[J]. 包装工程, 2016(10): 168-169.

[2] Dai Lianci, Qi Kang. Encyclopedia of China. Architecture,Landscape, Urban Planning [M]. Beijing: China Encyclopedia Publishing House, 1988. ] 戴念慈,齐康.建筑学.中国大百科全书.建筑、园林、城市规 划[M].北京:中国大百科全书出版社,1988.

[3] Liu Yue. Comparative Study of Chinese and Western Architectural Aesthetics[D]. Shanghai, Fudan University，2004. 刘月.中西建筑美 学比较研究[D]. 上海:复旦大学,2004.
[4] Wang Shiren. Body Composition of Chinese Architectural Culture and Its development[J]. Journal of Architecture, 1988(3):38. 王世仁. 中国 建筑文化的机体构成与运动[J]. 建筑学报, 1988(3):38.

[5] Guan Lihua. Recognition "decoration": The Meaning of Decoration and Its Essence[J]. Journal of Yunnan Art Institute,2003:29-30. 管丽华.重 识“装饰”一谈装饰的含义与本质 [J].云南艺术学院学报,2003:2930

[6] Chang Qin. Introduction of Architectural Anthropology[J]. Journal of Architecture, 1992:40. 常青.建筑人类学发凡[J].建筑学报,1992:40.

[7] Hang Jian, Zhang Fuye, Sun Jian-jun. Art of Decoration[M]. Nanchang Jiangxi Fine Arts Publishing House, 2001. 杭间,张夫也,孙建君.装饰 的艺术 $[\mathrm{M}]$. 南昌:江西美术出版社,2001.

[8] LI Li, Liu Chang, Kang Jun-feng. Gradual Disappearance in Industrial Product Based on Gestalt Psychology[J]. Packaging Engineering, 2015(14):47. 李理, 刘畅, 康俊峰. 基于格式塔心理学的工业产品渐消 面设计研究[J]. 包装工程, 2015(14):47.

[9] Liu Guang. Contrast of Space Imagery between Chinese and Western Traditional Architecture Decoration[J]. Decoration, 2004, 2(25):71 刘冠.中西传统建筑装饰的空间意象对比[J]. 装饰, 2004, 2(25):71. 